OPEN ACCESS

Edited by:

Haotian Lin,

Sun Yat-Sen University, China

Reviewed by:

Francesco Maria D'Alterio, Imperial College Healthcare NHS

Trust, United Kingdom

Alessandro Meduri,

University of Messina, Italy

Karim Mohamed-Noriega,

Autonomous University of Nuevo

León, Mexico

*Correspondence:

Yanan Zhu

2313070@zju.edu.cn

Specialty section

This article was submitted to

Ophthalmology

a section of the journal

Frontiers in Medicine

Received: 16 May 2021 Accepted: 21 October 2021

Published: 26 November 2021

Citation:

Zhong Y, Yu Y, Li J, Lu B, Li S and Zhu Y (2021) Accuracy of Intraocular

Lens Power Calculation Formulas in Pediatric Cataract Patients: A

Systematic Review and

Meta-Analysis. Front. Med. 8:710492.

doi: 10.3389/fmed.2021.710492

\section{Accuracy of Intraocular Lens Power Calculation Formulas in Pediatric Cataract Patients: A Systematic Review and Meta-Analysis}

\author{
Yueyang Zhong, Yibo Yu, Jinyu Li, Bing Lu, Su Li and Yanan Zhu* \\ School of Medicine, Eye Center of the Second Affiliated Hospital, Zhejiang University, Hangzhou, China
}

Background: Among the various intraocular lens (IOL) power calculation formulas available in clinical settings, which one can yield more accurate results is still inconclusive. We performed a meta-analysis to compare the accuracy of the IOL power calculation formulas used for pediatric cataract patients.

Methods: Observational cohort studies published through April 2021 were systematically searched in PubMed, Web of Science, and EMBASE databases. For each included study, the mean differences of the mean prediction error and mean absolute prediction error (APE) were analyzed and compared using the random-effects model.

Results: Twelve studies involving 1,647 eyes were enrolled in the meta-analysis, and five formulas were compared: Holladay 1, Holladay 2, Hoffer Q, SRK/T, and SRK II. Holladay 1 exhibited the smallest APE (0.97; 95\% confidence interval [Cl]: 0.92-1.03). For the patients with an axial length (AL) less than $22 \mathrm{~mm}$, SRK/T showed a significantly smaller APE than SRK II (mean difference [MD]: $-0.37 ; 95 \% \mathrm{Cl}$ : -0.63 to -0.12 ). For the patients younger than 24 months, SRK/T had a significantly smaller APE than Hoffer Q (MD: $-0.28 ; 95 \% \mathrm{Cl}:-0.51$ to -0.06$)$. For the patients aged 24-60 months, SRK/T presented a significantly smaller APE than Holladay 2 (MD: $-0.60 ; 95 \% \mathrm{Cl}:-0.93$ to -0.26 ).

Conclusion: Due to the rapid growth and high variability of pediatric eyes, the formulas for IOL calculation should be considered according to clinical parameters such as age and AL. The evidence obtained supported the accuracy and reliability of SRK/T under certain conditions.

Systematic Review Registration: PROSPERO, identifier: INPLASY202190077.

Keywords: pediatric cataract, calculation formula, intraocular lens power, prediction error, meta-analysis

\section{INTRODUCTION}

Pediatric cataract accounts for $5-20 \%$ of the global cases of childhood blindness (1). The etiology of pediatric cataract is diverse, which includes genes mutations and various disruptive factors during the embryonic to postnatal stages (2). With the development of modern diagnostic technology, cataract surgical techniques and intraocular lens (IOL) designs, pediatric cataract surgery has been recommended as a safe and effective intervention for optical correction in infants and young children $(1,3,4)$. Nevertheless, controversies still exist on the timing of intervention, IOL implantation, and postoperative management for 
pediatric cataract. Even with a successful cataract surgery, it is still challenging to achieve the desired refractive outcomes in children. Pediatric eyes generally have shorter axial lengths (ALs), higher keratometry values, and smaller anterior chamber depths (ACD). Distinct from the eyes of an adult, pediatric eyes are characterized by rapid growth and constantly varying parameters, which may result in significant refractive change during the postoperative optical rehabilitation $(3,5)$. Aside from that, the inaccurate measurements of the parameters of children due to poor cooperation and fixation also complicates the calculation of IOL power for pediatric cataract patients.

At present, the IOL power calculation formulas applied in pediatric patients were derived from the data of adult eyes, which may be impractical for application in the eyes of children. The second-generation SRK II formula is a regression formula adjusted for AL and keratometry that was commonly used (6). Subsequently, the third-generation formula of Holladay 1 (7) and Hoffer Q (8) formulas introduced ACD and corneal curvature into the calculation. Another third-generation formula, SRK/T (9), is a non-linear theoretical formula optimized for postoperative $\mathrm{ACD}$, retinal thickness, $\mathrm{AL}$, and corneal refractive index. Thereafter, Holladay 2, a fourth-generation formula, takes the effective lens position and characteristics of patients into account to achieve personalized calculation (10). In adults, the Holladay 2 formula has been considered as the most accurate for eyes with an AL of $22-26 \mathrm{~mm}$ (11). The Haigis formula showed superiority over other formulas in short eyes of the adults $(\mathrm{AL}<22 \mathrm{~mm}$ ) (12), while the SRK/T is considered optimal for long eyes (AL > $26 \mathrm{~mm}$ ) (13).

Although the predictability of the IOL formulas for adults has been studied extensively, controversies still exist regarding the most appropriate IOL calculation formula for pediatric cataract patients $(12,14-17)$. For example, Andreo et al. (18) and Neely et al. (19) did not report a significant association between IOL formulas and refractive prediction error. On the other hand, Nihalani and Vanderveen (20) suggested that Hoffer Q was the most accurate formula, whereas Kekunaya et al. (21) found that the SRK II formula was superior to the other formulas. To date, the comparisons of the predictability of the IOL calculation formulas for pediatric cataract patients have yielded inconsistent results. We therefore conducted an initial and comprehensive systematic review and meta-analysis to evaluate and compare the refractive prediction performances of the different IOL power calculation formulas in pediatric cataract patients.

\section{MATERIALS AND METHODS}

This meta-analysis was designed, implemented, and performed in accordance with the meta-analysis of observational studies in epidemiology (MOOSE) protocol (22), and is reported herein following the preferred reporting items for systematic reviews (PRISMA) guidelines (23). The protocol for this systematic review was registered on International Platform of Registered Systematic Review and Meta-analysis Protocols (INPLASY) (registration number: INPLASY202190077).

\section{Search Strategy}

Two independent investigators (YZ and YY) systematically searched the databases of PubMed, Web of Science, and EMBASE for cohort studies published through April, 2021. The following search strategy was used: (pediatric cataract) AND (calculate OR formula) AND (IOL OR IOL). Only articles published in English and full-text journal articles of original studies were included. Furthermore, the references cited in the relevant articles were reviewed for additional eligible publications.

\section{Eligibility Criteria}

Studies that met the following criteria were included in our meta-analysis: (i) included pediatric cataract patients who underwent cataract extraction and primary posterior chamber IOL implantation; (ii) compared at least two types of the target IOL power calculation formula (Holladay 1, Holladay 2, Hoffer $\mathrm{Q}, \mathrm{SRK} / \mathrm{T}$, and SRK II); and (iii) provided either prediction error (PE) or APE values (with 95\% confidence intervals [CIs]). We excluded reviews, non-comparative studies, case reports, studies that lacked sufficient data, and other non-relevant publications.

\section{Data Extraction}

Two independent investigators (YZ and YY) conducted an initial screening of titles and abstracts and then evaluated the full texts of the eligible studies. Any discrepancies were resolved through group discussion. The data were extracted in a standardized data collection form including the following information from each included study: first author, year of publication, study location, study design, sample size, gender, age, AL, follow-up duration, IOL calculation formulas used, and the PE and/or APE values with their 95\% CIs.

\section{Quality Assessment}

Quality assessment was performed using the revised quality assessment of diagnostic accuracy studies (QUADAS-2) tool (24). QUADAS-2 is applied in four phases: summarizing the review question, tailoring the tool and producing review-specific guidance, constructing a flow diagram for the primary study, and judging bias and applicability. For judgments of risk of bias and applicability, four domains discussing patient selection, index test, reference standard, and flow and timing were assessed with 14 signaling questions.

\section{Statistical Analysis}

In this meta-analysis, PE and/or APE with 95\% CI was considered as the common measure of comparison of the different IOL calculation formulas across studies. The random-effects model (DerSimonian-Laird method) was used to calculate the summarized mean differences (MDs) and their corresponding 95\% CIs $(25,26)$.

The heterogeneity among the studies was estimated using the $I^{2}$ statistic, with cutoff values representing low (25\%), moderate (50\%), and high (75\%) degrees of heterogeneity (27). To explore the potential confounding factors, we performed subgroup analyses based on different ages and ALs. 


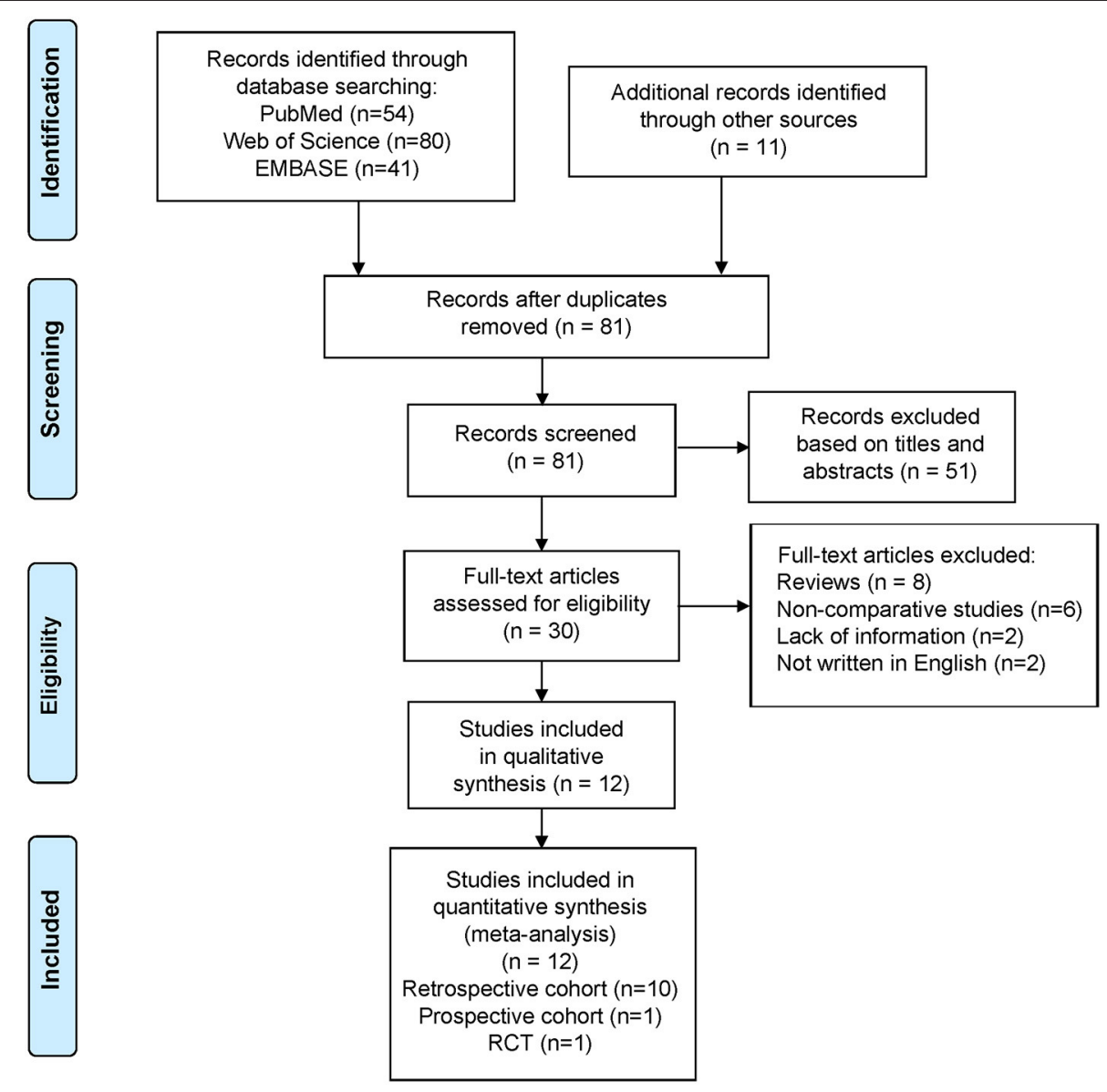

FIGURE 1 | Flowchart depicting the literature search and selection strategy.

\section{Sensitivity Analysis and Publication Bias}

Sensitivity analyses were performed by omitting one study at a time and calculating a pooled estimate for the remainder of the studies to determine if the results were markedly affected by a single study. The publication bias was evaluated by the application of Egger's linear regression test and Begg's rank correlation test with the significance set at $p<0.10$ (28, 29). All the statistical analyses were performed using Stata (version 15.0; StataCorp LP, College Station, TX, USA). All the tests were two tailed, and differences with $p<0.05$ were considered significant.

\section{RESULTS}

\section{Search Process}

Of the 186 articles identified (54 from PubMed, 80 from Web of Science, 41 from EMBASE, and 11 from other sources), we excluded 105 duplicates and 69 studies that did not meet the aforementioned criteria (Figure 1). Eventually, we included 12 studies in the meta-analysis (11 cohort studies and one randomized comparative trial).

\section{Study Characteristics}

Table 1 summarizes the descriptive characteristics of the included studies. A total of 1,647 eyes from 12 studies were enrolled in our meta-analysis (20,21, 30-39). Five of the studies were conducted in the United States, three in China, three in other Asian countries, and one in Canada. Ten studies (1,102 eyes) assessed the predictability of IOL calculation formula with Holladay 1, six studies (439 eyes) with Holladay 2, 12 studies (1,647 eyes) with Hoffer Q and SRK/T, and eight studies (1,319 eyes) with SRK II. The quality assessment results using the QUADAS-2 tool indicated a low risk of bias of the included studies (Supplementary Table 1 and Figure 2).

\section{Comparison of the APEs of the Different Formulas}

The APEs of the studied formulas are shown in Supplementary Figure 1. All the formulas showed inevitable APE in pediatric eyes. Holladay 1 demonstrated the smallest APE (0.97; 95\% CI: 0.92-1.03), followed by Holladay 2 (APE: 1.05; 95\% CI: 0.94-1.17) and Hoffer Q (APE: 1.05; 95\% CI: 1.00-1.11). Among all the studied formulas, SRK II showed the largest APE 
TABLE 1 | Characteristics of the included studies $(n=12)$.

\begin{tabular}{|c|c|c|c|c|c|c|c|c|}
\hline References & Country & Study design & $\begin{array}{c}\text { Eyes } \\
\text { (n) }\end{array}$ & $\begin{array}{c}\text { Sex } \\
\text { (M/F) }\end{array}$ & Age (months) ${ }^{a}$ & Axial length $(\mathrm{mm})^{\mathrm{b}}$ & Measurement (weeks) ${ }^{c}$ & $\begin{array}{l}\text { IOL power } \\
\text { calculation } \\
\text { formulas }\end{array}$ \\
\hline $\begin{array}{l}\text { Eppley et al., } \\
\text { (30) }\end{array}$ & US & Retrospective cohort & 64 & $32 / 32$ & $70.8 \pm 42.7$ (17.5-185.4) & $22.6 \pm 1.6(19.6-26.3)$ & $7.2 \pm 3.6(3-16)$ & $\begin{array}{l}\text { Holladay 2, Hoffer } \\
\text { Q, SRK/T, Barrett }\end{array}$ \\
\hline $\begin{array}{l}\text { Chang et al., } \\
\text { (31) }\end{array}$ & China & Retrospective cohort & 68 & $35 / 33$ & $34.1 \pm 24.6$ & $21.1 \pm 1.4$ & 4 & $\begin{array}{l}\text { Holladay } 1 \text {, } \\
\text { Holladay 2, Hoffer } \\
\text { Q, SRK/T, SRK II, } \\
\text { Haigis, Barrett }\end{array}$ \\
\hline Kou et al., (39) & China & Prospective cohort & 102 & NA & $41.4(6-84)$ & $21.8(18.1-25.9)$ & 4 & $\begin{array}{l}\text { Holladay } 1 \text {, } \\
\text { Holladay } 2 \text {, Hoffer } \\
\text { Q, SRK/T, Haigis }\end{array}$ \\
\hline Li et al., (32) & China & Retrospective cohort & 377 & 194/183 & $55.2 \pm 28.0(9-150)$ & $21.5 \pm 1.9(17.9-31.5)$ & $6.0 \pm 2.7(3.7-14.4)$ & $\begin{array}{l}\text { Holladay } 1, \text { Hoffer } \\
\text { Q, SRK/T, SRK II }\end{array}$ \\
\hline Lee et al., (33) & Korea & Retrospective cohort & 481 & $182 / 156$ & $643.6 \pm 30.1(11-210)$ & $21.3 \pm 1.7(15.2-27.5)$ & $4-10$ & $\begin{array}{l}\text { Hoffer Q, SRK/T, } \\
\text { SRK II }\end{array}$ \\
\hline $\begin{array}{l}\text { Vasavada et al., } \\
\text { (34) }\end{array}$ & US & Retrospective cohort & 117 & NA & $35.6 \pm 35.6(2.4-165.6)$ & $20.9 \pm 2.8(17.1-26.1)$ & $4.0 \pm 2.4(2.0-6.8)$ & $\begin{array}{l}\text { Holladay } 1 \text {, } \\
\text { Holladay } 2 \text {, Hoffer } \\
\text { Q, SRK/T }\end{array}$ \\
\hline Joshi et al., (35) & Nepal & Retrospective cohort & 28 & $13 / 6$ & $79.2 \pm 48.0(24-168)$ & $19.2 \pm 0.9(17.1-20.0)$ & $>6$ & $\begin{array}{l}\text { Holladay } 1, \text { Hoffer } \\
\text { Q, SRK/T, SRK II }\end{array}$ \\
\hline $\begin{array}{l}\text { Vanderveen et } \\
\text { al., (36) }\end{array}$ & US & $\mathrm{RCT}$ & 43 & NA & $2.5 \pm 1.5$ & $18.1 \pm 1.1$ & 4 & $\begin{array}{l}\text { Holladay } 1 \text {, } \\
\text { Holladay } 2 \text {, Hoffer } \\
\text { Q, SRK/T, SRK II }\end{array}$ \\
\hline $\begin{array}{l}\text { Kekunnaya et } \\
\text { al., (21) }\end{array}$ & India & Retrospective cohort & 128 & $41 / 43$ & $11.7 \pm 6.2(1.5-23)$ & $19.9 \pm 1.7(16.3-25.7)$ & 4 & $\begin{array}{l}\text { Holladay } 1 \text {, Hoffer } \\
\text { Q, SRK/T, SRK II }\end{array}$ \\
\hline $\begin{array}{l}\text { Trivedi et al., } \\
\text { (37) }\end{array}$ & US & Retrospective cohort & 45 & NA & $46.8 \pm 34.8(1.2-124.8)$ & $21.7 \pm 2.0(16.8-27.6)$ & $7.8 \pm 2.8(3.8-15.0)$ & $\begin{array}{l}\text { Holladay } 1 \text {, } \\
\text { Holladay } 2 \text {, Hoffer } \\
\text { Q, SRK/T }\end{array}$ \\
\hline $\begin{array}{l}\text { Nihalani and } \\
\text { VanderVeen, } \\
\text { (20) }\end{array}$ & US & Retrospective cohort & 135 & $51 / 45$ & $76.8(1.1-216)$ & $22.2(17.7-27.8)$ & $4-8$ & $\begin{array}{l}\text { Holladay } 1, \text { Hoffer } \\
\text { Q, SRK/T, SRK II }\end{array}$ \\
\hline $\begin{array}{l}\text { Mezer et al., } \\
\text { (38) }\end{array}$ & Canada & Retrospective cohort & 59 & $34 / 15$ & $89.0(22-216)$ & 26.7 (19.2-26.7) & $8-24$ & $\begin{array}{l}\text { Holladay 1, Hoffer } \\
\text { Q, SRK/T, SRK II }\end{array}$ \\
\hline
\end{tabular}

M, Male; F, Female; IOL, intraocular lens; RCT, randomized comparative trial; NA, not available.

${ }^{a}$ Age: mean \pm standard deviation (SD) and/or range.

${ }^{b}$ Axial length: mean $\pm S D$ and/or range.

${ }^{c}$ Measurement: mean $\pm S D$ and/or range.

of $(1.34 ; 95 \%$ CI: $1.28-1.41)$. As shown in Table 2, the MDs of PEs, APEs, and relative risks of APE $<0.5 \mathrm{D}$ of the different formulas were not significant. However, the pooled results were characterized by substantial heterogeneity and warrants further subgroup analysis.

The MDs of the APEs of the different formulas are presented in Figure 3. Four studies compared the predictability levels of Holladay 1 and Holladay 2. The APEs of these formulas were not significantly different (MD: -0.06 ; 95\% CI: -0.23 to 0.11 ; Figure 3A), with low heterogeneity $\left(I^{2}=0\right)$. Nine studies compared the APEs of Holladay 1 and Hoffer Q. The pooled results indicated no significant difference in APEs (MD: -0.11 ; $95 \%$ CI: -0.23 to 0.01 ; Figure $3 B$ ), with moderate heterogeneity $\left(I^{2}=35.2 \%\right)$. Sensitivity analysis was conducted by omitting one study at a time, and after excluding the study by Kekunnaya et al. (21) the heterogeneity decreased significantly (from 35.2\%-0). However, the APEs of Holladay 1 and Hoffer Q were still comparable (MD: -0.04 ; 95\% CI: -0.13 to 0.05; Supplementary Table 2). In addition, after excluding the study by $\mathrm{Li}$ et al. (32), the APE became significantly smaller with Holladay 1 than with Hoffer Q (MD: -0.15 ; 95\% CI: -0.27 to -0.02 ; Supplementary Figure 2). The nine studies comparing the Holladay 1 and SRK/T formulas showed no significant difference in APE (MD: $-0.01 ; 95 \% \mathrm{CI}:-0.09$ to 0.08 ; Figure $3 \mathrm{C}$ ), and no heterogeneity $\left(I^{2}=0\right)$ was detected for the pooled analysis. For Holladay 1 and SRK II, seven studies were analyzed, and the APEs of the groups were found to be similar (MD: $-0.07 ; 95 \% \mathrm{CI}$ : -0.40 to 0.27 ; Figure 3D) with high heterogeneity $\left(I^{2}=89.4 \%\right)$. Nevertheless, when the study by Kekunnaya et al. (21) was excluded, the heterogeneity decreased from 89.4 to $58.1 \%$ and the pooled results indicated a significantly smaller APE with Holladay 1 than with SRK II (MD: -0.23 ; $95 \%$ CI: -0.43 to -0.04 ; Supplementary Figure 2).

Four studies compared the predictability levels of Holladay 2 and Hoffer Q. No significant difference was found in the groups' 


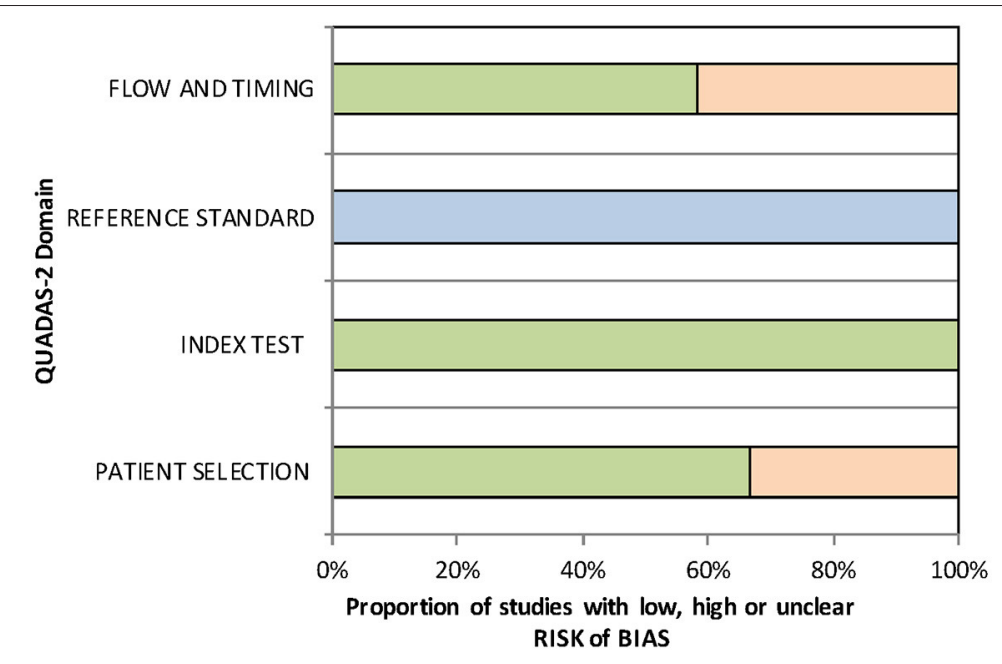

Low $\square$ High $\square$ Unclear

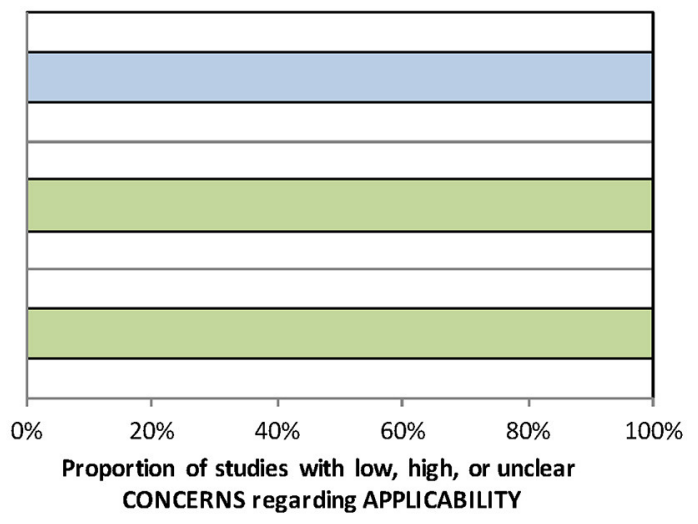

FIGURE 2 | QUADAS-2 quality assessment of the included studies.

TABLE 2 | Mean difference of prediction error (PE), absolute prediction error (APE), and relative risk of APE prediction < 0.5 D.

\begin{tabular}{|c|c|c|c|c|c|c|c|c|c|}
\hline \multirow[t]{2}{*}{ Formula comparison } & \multicolumn{3}{|c|}{ PE } & \multicolumn{3}{|c|}{ APE } & \multicolumn{3}{|c|}{ APE prediction < $0.5 \mathrm{D}$} \\
\hline & $\mathbf{N}$ & MD (95\% Cl) & $I^{2}$ & $\mathbf{N}$ & MD (95\% Cl) & $I^{2}$ & $\mathbf{N}$ & RR (95\% Cl) & $I^{2}$ \\
\hline Holladay 1 vs. Holladay 2 & 3 & $0.03(-0.22,0.29)$ & $45.1 \%$ & 4 & $-0.06(-0.23,0.11)$ & 0 & 2 & $0.98(0.86,1.11)$ & 0 \\
\hline Holladay 1 vs. Hoffer Q & 7 & $-0.05(-0.22,0.12)$ & $63.2 \%$ & 9 & $-0.11(-0.23,0.01)$ & $35.2 \%$ & 5 & $0.99(0.94,1.06)$ & 0 \\
\hline Holladay 1 vs. SRK/T & 7 & $0.01(-0.11,0.13)$ & $30.7 \%$ & 9 & $-0.01(-0.09,0.08)$ & 0 & 5 & $1.00(0.94,1.07)$ & 0 \\
\hline Holladay 1 vs. SRK II & 5 & $0.02(-0.41,0.45)$ & $92.8 \%$ & 7 & $-0.07(-0.40,0.27)$ & $89.4 \%$ & 4 & $1.03(0.96,1.10)$ & $60.9 \%$ \\
\hline Holladay 2 vs. Hoffer Q & 4 & $-0.18(-0.47,0.01)$ & $26.2 \%$ & 4 & $-0.08(-0.33,0.18)$ & $53.8 \%$ & 2 & $1.04(0.91,1.19)$ & 0 \\
\hline Holladay 2 vs. SRK/T & 4 & $0.10(-0.16,0.35)$ & $58.3 \%$ & 4 & $0.13(-0.13,0.39)$ & $55.0 \%$ & 3 & $1.03(0.93,1.14)$ & 0 \\
\hline Hoffer Q vs. SRK/T & 9 & $0.17(-0.07,0.40)$ & $88.3 \%$ & 10 & $0.17(-0.01,0.35)$ & $79.8 \%$ & 5 & $1.01(0.95,1.07)$ & 0 \\
\hline Hoffer Q vs. SRK II & 6 & $0.17(-0.35,0.69)$ & $97.1 \%$ & 8 & $0.12(-0.24,0.48)$ & $94.4 \%$ & 4 & $1.04(0.97,1.11)$ & $74.0 \%$ \\
\hline SRK/T vs. SRK II & 6 & $0.04(-0.21,0.28)$ & $86.8 \%$ & 8 & $-0.09(-0.30,0.13)$ & $84.0 \%$ & 4 & $1.02(0.95,1.09)$ & $67.8 \%$ \\
\hline
\end{tabular}

$M D$, mean difference; $95 \% \mathrm{Cl}$, 95\% confidence interval; $R R$, relative risk.

APEs (MD: -0.08 ; 95\% CI: -0.33 to 0.18 ; Figure $3 E$ ) with moderate heterogeneity $\left(I^{2}=53.8 \%\right)$. The sensitivity analysis suggested that the study by Chang et al. (31) was the source of heterogeneity. The heterogeneity decreased to 0 when the study by Chang et al. (31) was excluded (MD: -0.18 ; $95 \% \mathrm{CI}:-0.38$ to 0.01; Supplementary Table 2). The four studies comparing the Holladay 2 and SRK/T formulas showed no significant difference in APE (MD: 0.13 ; $95 \% \mathrm{CI}:-0.13$ to 0.39 ; Figure $3 \mathrm{~F}$ ), and moderate heterogeneity $\left(I^{2}=55.0 \%\right)$ was detected. Ten studies were included to compare the APEs with Hoffer Q and with SRK/T, and no significant difference was found (MD: 0.17; 95\% CI: -0.01 to 0.35 ; Figure $3 G$ ). After removing the study by Li et al. (32), the between-study heterogeneity decreased from $79.8 \%$ to $69.9 \%$, and the SRK/T formula presented a significantly smaller APE than the Hoffer Q formula (MD: $-0.21 ; 95 \%$ CI: -0.39 to -0.04 ; Supplementary Figure 2). With respect to Hoffer Q and SRK II formulas, eight studies were included in the meta-analysis. No significantly different APE was found (MD: 0.12 ; $95 \%$ CI: -0.24 to 0.48 ; Figure $3 \mathrm{H}$ ) with substantial heterogeneity $\left(I^{2}=94.4 \%\right)$. The APEs with SRK/T and with SRK II formulas were compared in eight studies and were not significantly different (MD: $-0.09 ; 95 \% \mathrm{CI}$ : -0.30 to 0.13 ; Figure 3I). Substantial between-study heterogeneity was detected $\left(I^{2}=84.0 \%\right)$.

\section{Subgroup Analyses}

Subgroup analyses were performed based on different ranges of age and AL. As shown in Table 3, three studies compared the PEs of Holladay 2 and Hoffer Q in patients with an AL smaller than $22 \mathrm{~mm}$. The pooled results indicated a significantly smaller PE with Holladay 2 than with Hoffer Q (MD: -0.37 ; 95\% CI: -0.65 to -0.10 ), with no between-study heterogeneity. In addition, for the patients with an AL of 22-24.5 mm, a significantly larger PE was found with Hoffer Q than with SRK/T (MD: 0.25; 95\% CI: 0.06 to 0.44$)$.

The results of the subgroup analyses of APEs based on different ranges of age and AL are presented in Table 4. For the patients younger than 24 months, a significantly smaller 


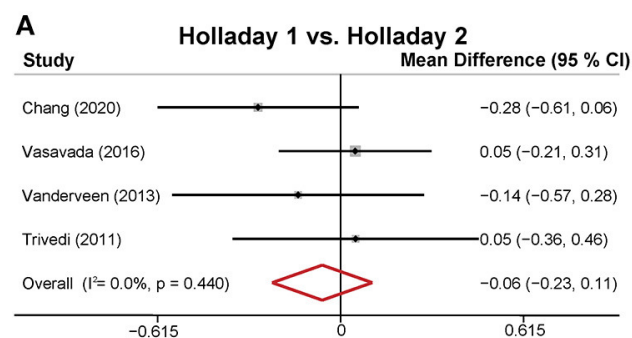

\section{C}
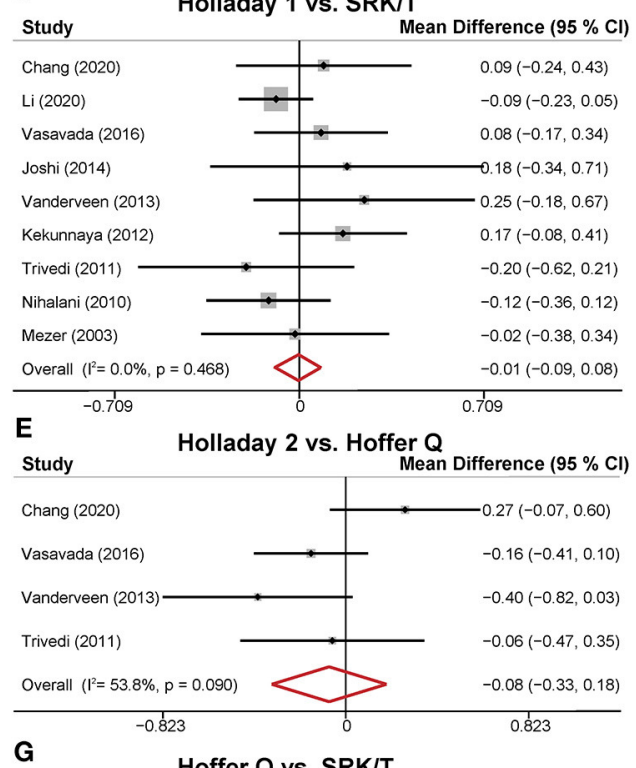

G $\quad$ Hoffer Q vs. SRK/T Mean Difference $(95 \% \mathrm{Cl})$

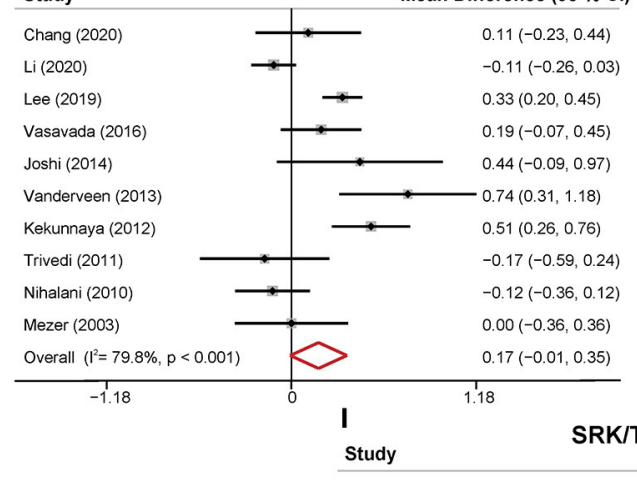

Study $\quad$ SRK $/$ vs. SRK II

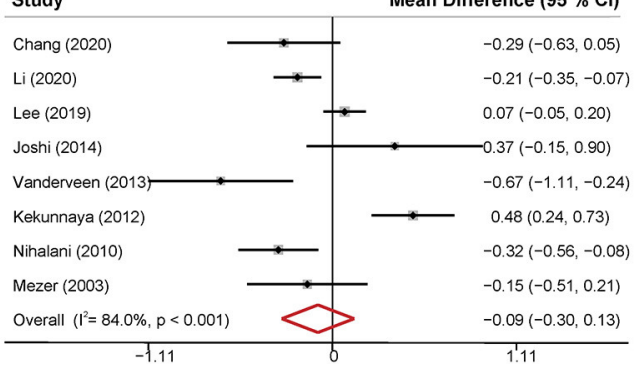

FIGURE 3 | Forest plot of the mean difference (MD) of absolute prediction error (APE) of the different formulas. (A) Holladay 1 vs. Holladay 2; (B) Holladay 1 vs. Hoffer Q; (C) Holladay 1 vs. SRK/T; (D) Holladay 1 vs. SRK II; (E) Holladay 2 vs. Hoffer Q; (F) Holladay 2 vs. SRK/T; (G) Hoffer Q vs. SRK/T; (H) Hoffer Q vs. SRK II; (I) SRK/T vs. SRK II.
B

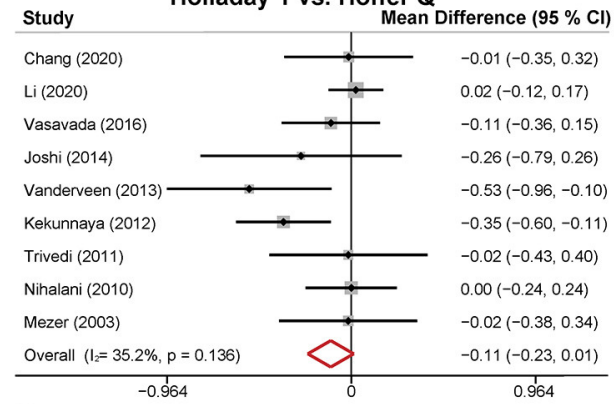

D Holladay 1 vs. SRK II
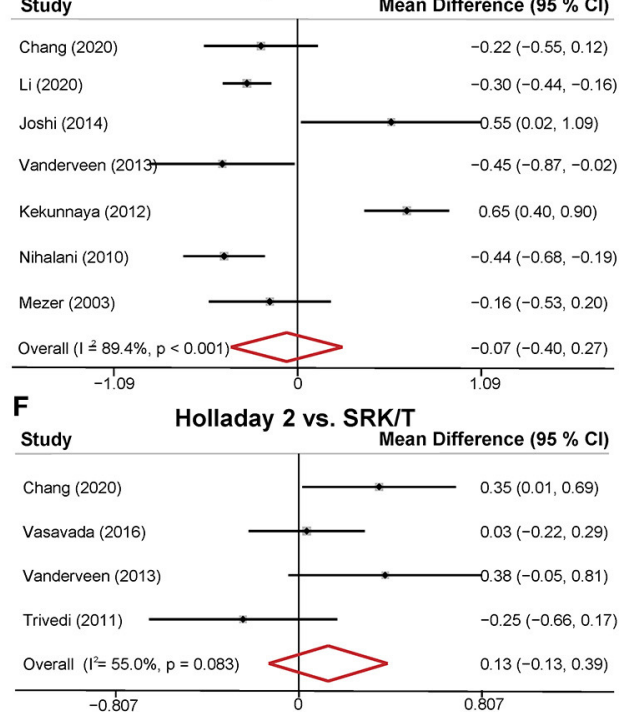

$\begin{array}{ll}\text { H } & \text { Hoffer Q vs. SRK II } \\ \text { Study } & \end{array}$

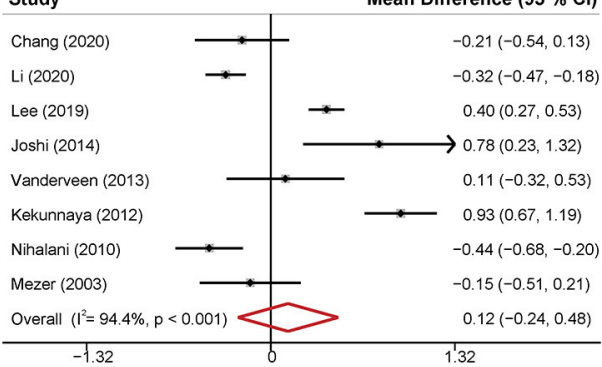

$-1.32$ 
TABLE 3 | Mean difference of prediction error (PE) between groups stratified by age and axial length.

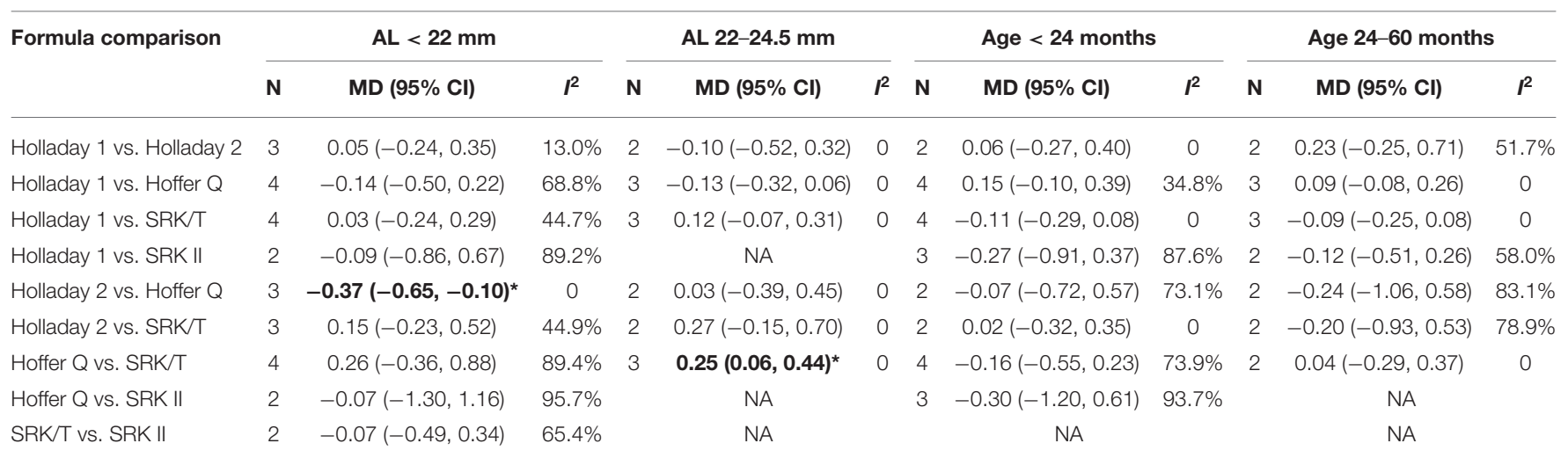

AL, axial length; MD, mean difference; 95\% Cl, 95\% confidence interval; NA, not available.

*Indicates statistical significance.

TABLE 4 | Mean difference of absolute prediction error (APE) between groups stratified by age and axial length.

\begin{tabular}{|c|c|c|c|c|c|c|c|c|c|c|c|c|}
\hline \multirow[t]{2}{*}{ Formula comparison } & \multicolumn{3}{|c|}{$\mathrm{AL}<22 \mathrm{~mm}$} & \multicolumn{3}{|c|}{ AL 22-24.5 mm } & \multicolumn{3}{|c|}{ Age $<24$ months } & \multicolumn{3}{|c|}{ Age $24-60$ months } \\
\hline & $\mathbf{N}$ & MD (95\% Cl) & $I^{2}$ & $\mathbf{N}$ & MD (95\% Cl) & $I^{2}$ & $\mathbf{N}$ & MD (95\% Cl) & $I^{2}$ & $\mathbf{N}$ & MD (95\% Cl) & $I^{2}$ \\
\hline Holladay 1 vs. Holladay 2 & 4 & $-0.09(-0.33,0.14)$ & 0 & 2 & $0.15(-0.28,0.57)$ & 0 & 2 & $-0.25(-0.58,0.09)$ & 0 & 2 & $-0.25(-0.58,0.08)$ & 0 \\
\hline Holladay 1 vs. Hoffer Q & 5 & $-0.15(-0.38,0.08)$ & $41.6 \%$ & 3 & $0.02(-0.17,0.21)$ & 0 & 4 & $-0.18(-0.38,0.03)$ & $14.4 \%$ & 3 & $0.15(-0.15,0.46)$ & $51.6 \%$ \\
\hline Holladay 1 vs. SRK/T & 5 & $-0.01(-0.19,0.16)$ & $11.2 \%$ & 3 & $-0.04(-0.29,0.21)$ & $15.9 \%$ & 4 & $0.11(-0.08,0.29)$ & 0 & 3 & $0.15(-0.26,0.56)$ & $72.4 \%$ \\
\hline Holladay 1 vs. SRK II & 3 & $-0.39(-0.56,-0.21)^{*}$ & 0 & & NA & & 3 & $0.08(-0.58,0.74)$ & $88.6 \%$ & 2 & $-0.30(-0.48,-0.12)^{*}$ & 0 \\
\hline Holladay 2 vs. Hoffer Q & 4 & $-0.17(-0.48,0.14)$ & $43.1 \%$ & 2 & $0.08(-0.34,0.50)$ & 0 & 2 & $0.23(-0.11,0.56)$ & 0 & 2 & $0.54(0.21,0.88)^{\star}$ & 0 \\
\hline Holladay 2 vs. SRK/T & 4 & $0.21(-0.02,0.44)$ & 0 & 2 & $-0.42(-1.14,0.31)$ & $63.5 \%$ & 2 & $0.32(-0.01,0.66)$ & 0 & 2 & $0.60(0.26,0.93)^{\star}$ & 0 \\
\hline Hoffer Q vs. SRK/T & 5 & $0.21(-0.19,0.60)$ & $79.5 \%$ & 3 & $-0.22(-0.68,0.25)$ & $66.2 \%$ & 5 & $0.28(0.06,0.51)^{\star}$ & $48.5 \%$ & 4 & $0.09(-0.20,0.37)$ & $76.1 \%$ \\
\hline Hoffer Q vs. SRK II & 3 & $-0.24(-0.58,0.11)$ & $63.7 \%$ & & NA & & 4 & $0.28(-0.26,0.82)$ & $90.1 \%$ & 3 & $-0.03(-0.60,0.55)$ & $94.2 \%$ \\
\hline SRK/T vs. SRK II & 3 & $-0.37(-0.63,-0.12)^{\star}$ & $37.3 \%$ & & NA & & 4 & $0.07(-0.27,0.42)$ & $75.6 \%$ & 3 & $-0.09(-0.34,0.17)$ & $69.7 \%$ \\
\hline
\end{tabular}

AL, axial length; $M D$, mean difference; 95\% Cl, 95\% confidence interval; NA, not available.

*Indicates statistical significance.

APE was found with SRK/T than with Hoffer Q (MD: -0.28 ; 95\% CI: -0.51 to -0.06$)$. For the patients aged between 24 and 60 months, Holladay 1 formula showed a smaller APE than SRK II (MD: -0.30 ; 95\% CI: -0.48 to -0.12 ). Furthermore, Holladay 2 formula showed a significantly higher APE than Hoffer Q (MD: 0.54; 95\% CI: 0.21 to 0.88 ) and SRK/T (MD: $0.60 ; 95 \%$ CI: 0.26 to 0.93 ). When stratified by AL, a significantly smaller APE was found with Holladay 1 than with SRK II (MD: $-0.39 ; 95 \%$ CI: -0.56 to -0.21 ) among the patients with an AL smaller than $22 \mathrm{~mm}$. SRK/T exhibited better predictability than SRK II (MD: $-0.37 ; 95 \%$ CI: -0.63 to -0.12 ).

\section{Publication Bias}

The publication bias was tested using Egger's linear regression test and the Begg's rank correlation test (Supplementary Table 3). The results did not show significant bias in any of the comparisons, which was consistent with the funnel plots (Supplementary Figures 3, 4).

\section{DISCUSSION}

In summary, the current meta-analysis included 12 studies involving 1,647 eyes with pediatric cataract, providing the most up-to-date and comprehensive evidence of the predictability levels of the different IOL power calculation formulas. Briefly, SRK/T formula exhibited a significantly smaller APE than Hoffer $\mathrm{Q}$ among the patients younger than 24 months. Among the patients aged 24-60 months, both SRK/T and Hoffer Q formulas were superior to Holladay 2, and SRK II was outperformed by Holladay 1. For patients with $\mathrm{AL}<22 \mathrm{~mm}$, SRK/T and Holladay 1 showed a smaller APE than SRK II.

Despite the rapid development of biometrical measurement techniques, the accurate measurement of pediatric parameters remains challenging due to the poor cooperation by the children and their ever-changing eye conditions. Previous studies have indicated that the ALs of the children's eyes grew rapidly within the first 2 years and became relatively stable at the adult's level until the age of 5 (40-42). Other structures including ACD and corneal curvature, which are 
important parameters in calculating IOL power, also underwent significant changes in the first 42 months (42). Consequently, as previous studies have suggested, age, AL, keratometry, and ACD are the major factors affecting refractive error $(21,31,32,34)$. Indeed, the results of our meta-analysis based on all the included samples were characterized by substantial heterogeneity, which may be attributed to the different eye conditions of the patients included in the metaanalysis.

The postoperative refractive error was largely influenced by the $\mathrm{AL}$ measurement, postoperative $\mathrm{ACD}$, and corneal power errors $(43,44)$. In our subgroup analysis, the $\mathrm{AL}$ subgroups were divided into $<22 \mathrm{~mm}$ and $22-24.5 \mathrm{~mm}$. On the basis of the previous evidence, the use of Holladay 2 and Hoffer Q for adult patients with short eyes has been recommended $(11,45)$. Our results indicated that among the patients with an $\mathrm{AL}<22 \mathrm{~mm}$, the fourth-generation of Holladay 2 formula outperformed Hoffer Q. Similarly, in short eyes of adults, Hoffer $\mathrm{Q}$ has been reported to have better predictivity than Holladay 2 (11). A previous metaanalysis that focused on short eyes of adults found that Holladay 2, which, unlike other formulas, incorporates patients' additional biometrical data, produced the smallest mean APE (12). Furthermore, in accordance with the previous evidence, SRK II was found to be inferior to Holladay 1 and SRK/T in our meta-analysis $(6,8,19)$. The older second-generation formula SRK II was based on a regression model and has been reported to provide the least accuracy $(8,10)$. For pediatric patients with a longer $\mathrm{AL}(22-24.5 \mathrm{~mm})$, the thirdgeneration SRK/T formula had a significantly smaller PE than Hoffer Q, with no heterogeneity observed, suggesting the robustness of the results. The results from adults also suggested that SRK/T outperformed Hoffer Q in eyes with a moderate AL (17).

The multiple linear regression analyses from previous studies have demonstrated that age is significantly associated with postoperative refractive error $(21,32,35,39)$. The current metaanalysis included pediatric patients aged 1.1-216 months, which covers the whole period of the eye development pf a child. As a child grows, the refractive status changes significantly due to the elongation of the $\mathrm{AL}$, which mainly occurs in the first 2 years of life $(46,47)$. Therefore, the age subgroups were divided into younger than 24 months and 24-60 months. In the patients younger than 24 months, SRK/T was more accurate than Hoffer Q. The SRK/T formula is a non-linear theoretical formula empirically optimized for ACD, AL, retinal thickness, and corneal curvature (9). However, as a child ages, the expected significant myopic shift should be taken into account, and it is common to aim for hypermetropia instead of emmetropia, especially for children younger than 2 years old $(47,48)$. Therefore, the results of this study should be interpreted with caution, and the myopic shift after IOL implantation should be further considered. In the 24-60 months age subgroup, SRK/T and Hoffer Q showed a smaller APE than Holladay 2, and Holladay 1 showed a smaller APE than SRK II. Although no heterogeneity was observed, only two studies were included in each subgroup analysis, which precluded the reaching of a definitive conclusion. Taken together, a conclusion cannot be easily drawn, and age-specific IOL power calculation formulas for pediatric cataract patients should be further considered by the future studies.

Despite the potential errors of the IOL calculation formulas, eye parameters measurement deviation may also be a source of refractive error. For instance, lack of cooperation regarding precise fixation and centration, limited equipment designed for children's eyes, and the errors induced by the small size of pediatric eyes all contribute to the measurement inaccuracies (36, 38). Even under anesthesia, the measurement of keratometry was reported to be inaccurate due to lack of fixation (46). Therefore, more advanced measurement equipment designed specifically for pediatric patients are needed to achieve better accuracy.

Our meta-analysis evaluated and compared the predictability levels of the commonly applied IOL power calculation formulas in pediatric cataract patients. Nevertheless, the study was subject to several limitations. First, the pooled results were mainly based on retrospective cohort studies, which are subject to inevitable selection bias and confounding. We therefore assessed the risk of bias with QUADAS-2 and did not detect a significant risk of bias in the included studies. Second, there were moderate to substantial heterogeneity observed in some analyses. However, the sensitivity analyses indicated the study by Kekunnaya et al. (21) is the source of heterogeneity, and confirmed the stability of the results. Kekunnaya et al. (21) included data only from children younger than 24 months, which may partially explain the heterogeneity. Third, due to the significant variability of the study sample, we failed to reach a definitive conclusion for the whole study sample. However, the subgroup analyses based on age and AL have provided significant and meaningful results.

In summary, the present meta-analysis demonstrated high variability of refractive status among pediatric patients. Among the various IOL power calculation formulas currently available, SRK/T presented a relatively smaller postoperative refractive error under certain conditions. In real clinical practice, the clinical judgment should be based on the characteristics of the patient, the features of the formulas used, and the surgeon's experience. For pediatric cataract patients, more evidencebased and age-specific publications are needed to provide clinical guidelines for formula selection and accurate IOL power calculation.

\section{DATA AVAILABILITY STATEMENT}

The original contributions presented in the study are included in the article/Supplementary Material, further inquiries can be directed to the corresponding author.

\section{AUTHOR CONTRIBUTIONS}

YZhu conceived and designed the study. YZhong and YY performed literature search and data collection. YZhong, YY, and JL performed statistical analysis. YZhong, BL, and SL drafted the manuscript. YZhu revised the manuscript. All authors approved 
the final version to be published and agreed to be accountable for all aspects of the work.

\section{FUNDING}

This work was supported by the Program of National Natural Science Foundation of China (Grant No. 81970779 to YZhu), the Program of National Natural Science Foundation of China

\section{REFERENCES}

1. Liu Y-C, Wilkins M, Kim T, Malyugin B, Mehta JS. Cataracts. Lancet. (2017) 390:600-12. doi: 10.1016/S0140-6736(17)30544-5

2. Bremond-Gignac D, Daruich A, Robert MP, Valleix S. Recent developments in the management of congenital cataract. Ann Transl Med. (2020) 8:1545. doi: 10.21037/atm-20-3033

3. Liu Z, Long E, Chen J, Lin Z, Lin D, Wu X, et al. Developmental profile of ocular refraction in patients with congenital cataract: a prospective cohort study. Lancet. (2016) 388:S54. doi: 10.1016/S0140-6736(16)31981-X

4. Zwaan J, Mullaney PB, Awad A, al-Mesfer S, Wheeler DT. Pediatric intraocular lens implantation. Surgical results and complications in more than 300 patients. Ophthalmology. (1998) 105:112-118. doi: 10.1016/s0161-6420(98)91568-8

5. Plager DA, Kipfer H, Sprunger DT, Sondhi N, Neely DE. Refractive change in pediatric pseudophakia: 6-year follow-up. J Cataract Refract Surg. (2002) 28:810-5. doi: 10.1016/s0886-3350(01)01156-7

6. Sanders DR, Retzlaff J, Kraff MC. Comparison of the SRK II formula and other second generation formulas. J Cataract Refract Surg. (1988) 14:136-41. doi: 10.1016/s0886-3350(88)80087-7

7. Holladay JT, Prager TC, Chandler TY, Musgrove KH, Lewis JW, Ruiz RS, et al. three-part system for refining intraocular lens power calculations. J Cataract Refract Surg. (1988) 14:17-24. doi: 10.1016/s0886-3350(88)80059-2

8. Hoffer KJ. The Hoffer Q formula: a comparison of theoretic and regression formulas. J Cataract Refract Surg. (1993) 19:700-12. doi: 10.1016/s0886-3350(13)80338-0

9. Retzlaff JA, Sanders DR, Kraff MC. Development of the SRK/T intraocular lens implant power calculation formula. J Cataract Refract Surg. (1990) 16:333-40. doi: 10.1016/s0886-3350(13)80705-5

10. Olsen T. Calculation of intraocular lens power: a review. Acta Ophthalmol Scand. (2007) 85:472-85. doi: 10.1111/j.1600-0420.2007.00879.x

11. Hoffer KJ. Clinical results using the Holladay 2 intraocular lens power formula. I Cataract Refract Surg. (2000) 26:1233-7. doi: 10.1016/S0886-3350(00)00376-X

12. Wang Q, Jiang W, Lin T, Wu X, Lin H, Chen W. Meta-analysis of accuracy of intraocular lens power calculation formulas in short eyes. Clin Experiment Ophthalmol. (2018) 46:356-63. doi: 10.1111/ceo.13058

13. Sanders DR, Retzlaff JA, Kraff MC, Gimbel HV, Raanan MG. Comparison of the SRK/T formula and other theoretical and regression formulas. J Cataract Refract Surg. (1990) 16:341-6. doi: 10.1016/s0886-3350(13)80706-7

14. Darcy K, Gunn D, Tavassoli S, Sparrow J, Kane JX. Assessment of the accuracy of new and updated intraocular lens power calculation formulas in 10930 eyes from the UK National Health Service. J Cataract Refract Surg. (2020) 46:2-7. doi: 10.1016/j.jcrs.2019.08.014

15. Kane JX, Van Heerden A, Atik A, Petsoglou C. Intraocular lens power formula accuracy: Comparison of 7 formulas. J Cataract Refract Surg. (2016) 42:1490-500. doi: 10.1016/j.jcrs.2016.07.021

16. Cooke DL, Cooke TL. Comparison of 9 intraocular lens power calculation formulas. J Cataract Refract Surg. (2016) 42:1157-64. doi: $10.1016 /$ j.jcrs.2016.06.029

17. Melles RB, Holladay JT, Chang WJ. Accuracy of intraocular lens calculation formulas. Ophthalmology. (2018) 125:169-78. doi: 10.1016/j.ophtha.2017.08.027
(82070938 to YY), and the Program of National Natural Science Foundation of Zhejiang Province (LY20H120011 to YY).

\section{SUPPLEMENTARY MATERIAL}

The Supplementary Material for this article can be found online at: https://www.frontiersin.org/articles/10.3389/fmed. 2021.710492/full\#supplementary-material

18. Andreo LK, Wilson ME, Saunders RA. Predictive value of regression and theoretical IOL formulas in pediatric intraocular lens implantation. J Pediatr Ophthalmol Strabismus. (1997) 34:240-3.

19. Neely DE, Plager DA, Borger SM, Golub RL. Accuracy of intraocular lens calculations in infants and children undergoing cataract surgery. $J$ AAPOS Off Publ Am Assoc Pediatr Ophthalmol Strabismus. (2005) 9:160-5. doi: 10.1016/j.jaapos.2004.12.010

20. Nihalani BR, VanderVeen DK. Comparison of intraocular lens power calculation formulae in pediatric eyes. Ophthalmology. (2010) 117:1493-9. doi: 10.1016/j.ophtha.2009.12.031

21. Kekunnaya R, Gupta A, Sachdeva V, Rao HL, Vaddavalli PK, Om Prakash V. Accuracy of intraocular lens power calculation formulae in children less than two years. Am J Ophthalmol. (2012) 154:13-19.e2. doi: 10.1016/j.ajo.2011.11.031

22. Stroup DF, Berlin JA, Morton SC, Olkin I, Williamson GD, Rennie D, et al. Meta-analysis of observational studies in epidemiology: a proposal for reporting. Meta-analysis Of observational studies in epidemiology (MOOSE) group. JAMA. (2000) 283:2008-12. doi: 10.1001/jama.283.15.2008

23. Moher D, Liberati A, Tetzlaff J, Altman DG. PRISMA Group. Preferred reporting items for systematic reviews and meta-analyses: the PRISMA statement. PLoS Med. (2009) 6:e1000097. doi: 10.1371/journal.pmed.1000097

24. Whiting PF, Rutjes AWS, Westwood ME, Mallett S, Deeks JJ, Reitsma JB, et al. QUADAS-2 Group. QUADAS-2: a revised tool for the quality assessment of diagnostic accuracy studies. Ann Intern Med. (2011) 155:52936. doi: 10.7326/0003-4819-155-8-201110180-00009

25. DerSimonian R, Kacker R. Random-effects model for meta-analysis of clinical trials: an update. Contemp Clin Trials. (2007) 28:105-14. doi: 10.1016/j.cct.2006.04.004

26. Borenstein M, Hedges LV, Higgins JPT, Rothstein HR, A. basic introduction to fixed-effect and random-effects models for meta-analysis. Res Synth Methods. (2010) 1:97-111. doi: 10.1002/jrsm.12

27. Jackson D, White IR, Riley RD. Quantifying the impact of between-study heterogeneity in multivariate meta-analyses. Stat Med. (2012) 31:3805-20. doi: 10.1002/sim. 5453

28. Egger M, Davey Smith G, Schneider M, Minder C. Bias in metaanalysis detected by a simple, graphical test. BMJ. (1997) 315:629-34. doi: 10.1136/bmj.315.7109.629

29. Begg CB, Mazumdar M. Operating characteristics of a rank correlation test for publication bias. Biometrics. (1994) 50:1088-101.

30. Eppley SE, Arnold BF, Tadros D, Pasricha N, de Alba Campomanes AG. Accuracy of a universal theoretical formula for power calculation in pediatric intraocular lens implantation. J Cataract Refract Surg. (2021) 47:599-605. doi: 10.1097/j.jcrs.0000000000000495

31. Chang P, Lin L, Li Z, Wang L, Huang J, Zhao Y-E. Accuracy of 8 intraocular lens power calculation formulas in pediatric cataract patients. Graefes Arch Clin Exp Ophthalmol Albrecht Von Graefes Arch Klin Exp Ophthalmol. (2020) 258:1123-31. doi: 10.1007/s00417-020-04617-8

32. Li J, Liu Z, Wang R, Cheng H, Zhao J, Liu L, et al. Accuracy of intraocular lens power calculations in paediatric eyes. Clin Experiment Ophthalmol. (2020) 48:301-10. doi: 10.1111/ceo.13701

33. Lee BJ, Lee S-M, Kim JH Yu YS. Predictability of formulae for intraocular lens power calculation according to the age of implantation in paediatric cataract. Br J Ophthalmol. (2019) 103:106-11. doi: 10.1136/bjophthalmol-2017-311706 
34. Vasavada V, Shah SK, Vasavada VA, Vasavada AR, Trivedi RH, Srivastava S, et al. Comparison of IOL power calculation formulae for pediatric eyes. Eye Lond Engl. (2016) 30:1242-50. doi: 10.1038/eye.2016.171

35. Joshi P, Mehta R, Ganesh S. Accuracy of intraocular lens power calculation in pediatric cataracts with less than a $20 \mathrm{~mm}$ axial length of the eye. Nepal J Ophthalmol Biannu Peer-Rev Acad J Nepal Ophthalmic Soc NEPJOPH. (2014) 6:56-64. doi: 10.3126/nepjoph.v6i1.10773

36. Vanderveen DK, Trivedi RH, Nizam A, Lynn MJ, Lambert SR, Infant Aphakia Treatment Study Group. Predictability of intraocular lens power calculation formulae in infantile eyes with unilateral congenital cataract: results from the Infant Aphakia Treatment Study. Am J Ophthalmol. (2013) 156:1252-60.e2. doi: 10.1016/j.ajo.2013.07.014

37. Trivedi RH, Wilson ME, Reardon W. Accuracy of the Holladay 2 intraocular lens formula for pediatric eyes in the absence of preoperative refraction. $J$ Cataract Refract Surg. (2011) 37:1239-43. doi: 10.1016/j.jcrs.2011.01.021

38. Mezer E, Rootman DS, Abdolell M, Levin AV. Early postoperative refractive outcomes of pediatric intraocular lens implantation. J Cataract Refract Surg. (2004) 30:603-10. doi: 10.1016/j.jcrs.2003.07.002

39. Kou J, Chang P, Lin L, Li Z, Fu Y, Zhao Y-E. Comparison of the accuracy of IOL power calculation formulas for pediatric eyes in children of different ages. J Ophthalmol. (2020) 2020:8709375. doi: 10.1155/2020/8709375

40. Bach A, Villegas VM, Gold AS, Shi W, Murray TG. Axial length development in children. Int J Ophthalmol. (2019) 12:815-9. doi: 10.18240/ijo.2019.05.18

41. Hussain RN, Shahid F, Woodruff G. Axial length in apparently normal pediatric eyes. Eur J Ophthalmol. (2014) 24:120-3. doi: 10.5301/ejo.5000328

42. Capozzi P, Morini C, Piga S, Cuttini M, Vadalà P. Corneal curvature and axial length values in children with congenital/infantile cataract in the first 42 months of life. Invest Ophthalmol Vis Sci. (2008) 49:4774-8. doi: $10.1167 /$ iovs.07-1564

43. Olsen T. Sources of error in intraocular lens power calculation. J Cataract Refract Surg. (1992) 18:125-9. doi: 10.1016/s0886-3350(13)80917-0

44. Norrby S. Sources of error in intraocular lens power calculation. J Cataract Refract Surg. (2008) 34:368-76. doi: 10.1016/j.jcrs.2007.10.031
45. Fenzl RE, Gills JP, Cherchio M. Refractive and visual outcome of hyperopic cataract cases operated on before and after implementation of the Holladay II formula. Ophthalmology. (1998) 105:1759-64. doi: 10.1016/S0161-6420(98)99050-9

46. Eibschitz-Tsimhoni M, Tsimhoni O, Archer SM, Del Monte MA. Discrepancies between intraocular lens implant power prediction formulas in pediatric patients. Ophthalmology. (2007) 114:383-6. doi: 10.1016/j.ophtha.2006.06.063

47. O'Gallagher MK, Lagan MA, Mulholland CP, Parker M, McGinnity G, McLoone EM. Paediatric intraocular lens implants: accuracy of lens power calculations. Eye. (2016) 30:1215-20. doi: 10.1038/eye.2016.163

48. Flitcroft DI, Knight-Nanan D, Bowell R, Lanigan B, O'Keefe M. Intraocular lenses in children: changes in axial length, corneal curvature, and refraction. Br J Ophthalmol. (1999) 83:265-9. doi: 10.1136/bjo.83.3.265

Conflict of Interest: The authors declare that the research was conducted in the absence of any commercial or financial relationships that could be construed as a potential conflict of interest.

Publisher's Note: All claims expressed in this article are solely those of the authors and do not necessarily represent those of their affiliated organizations, or those of the publisher, the editors and the reviewers. Any product that may be evaluated in this article, or claim that may be made by its manufacturer, is not guaranteed or endorsed by the publisher.

Copyright (c) 2021 Zhong, Yu, Li, Lu, Li and Zhu. This is an open-access article distributed under the terms of the Creative Commons Attribution License (CC BY). The use, distribution or reproduction in other forums is permitted, provided the original author(s) and the copyright owner(s) are credited and that the original publication in this journal is cited, in accordance with accepted academic practice. No use, distribution or reproduction is permitted which does not comply with these terms. 